Fighting over friends and neighbors: The effect of inter-candidate geographic distance on intra-party competition

\title{
Put, Gert-Jan
}

2020-08

Put , G-J , von Schoultz , Å \& Isotalo, V 2020 , ' Fighting over friends and neighbors : The effect of inter-candidate geographic distance on intra-party competition ' , Political Geography , vol. 81 , 102219 . https://doi.org/10.1016/j.polgeo.2020.102219

http://hdl.handle.net/10138/327248

https://doi.org/10.1016/j.polgeo.2020.102219

cc_by_nc_nd

acceptedVersion

Downloaded from Helda, University of Helsinki institutional repository.

This is an electronic reprint of the original article.

This reprint may differ from the original in pagination and typographic detail.

Please cite the original version. 


\title{
Fighting over friends and neighbors: The effect of inter-candidate geographic distance on intra-party competition
}

\author{
Manuscript accepted for publication in Political Geography.
}

Gert-Jan Put, Université de Namur, gert-jan.put@unamur.be

Åsa von Schoultz, University of Helsinki, asa.vonschoultz@ helsinki.fi

Veikko Isotalo, University of Helsinki, veikko.isotalo@helsinki.fi

\begin{abstract}
Previous studies on intra-party competition have largely neglected the role played by geographic distance between co-partisan candidates. In this study, we argue that candidates who live further away from intra-party competitors on the same party list benefit electorally from their remoteness. Moreover, we contend that the electoral effectiveness of exhibiting local personal vote attributes - a theoretically and empirically well-established candidate strategy to cultivate personal votes - also depends on the geographical proximity of localized co-partisan candidates. Using a unique and untapped dataset of more than 5,000 Finnish election candidates' home address coordinates over four consecutive parliamentary elections (1999-2011), we run beta regression models to examine the effects of candidate remoteness and nearest candidates' local characteristics on intra-party vote shares. To measure the remoteness of a particular candidate, we develop a novel index based on the distribution of co-partisans over concentric circles around that candidate. The empirical analyses show that the effect of geographic remoteness depends on local party strength and the degree of urbanization: candidates particularly benefit from more distant co-partisans in party strongholds and rural and suburban municipalities. Moreover, all models confirm that nearby located localized copartisans decrease a candidate's own vote share. These findings have important implications for politicians' careers, party nomination strategies and future empirical research on intra-party competition.
\end{abstract}

Key words: intra-party competition, inter-candidate geographic distance, PVEA, party nomination strategies, Finland 


\section{Introduction}

After decades of prioritizing the inter-party dimension of political competition, the study of intra-party competition is rapidly gaining traction among electoral politics scholars. Patterns of competition within political parties, measured by vote distributions across candidates running under the same party label, provide a deeper understanding of how politics and elections are being played out. Identifying the determinants of individual candidate success help scholars and practitioners to classify electoral systems accurately and to understand the dynamics of political representation.

This article investigates which role inter-candidate distance plays in competition within parties, by analyzing geographic distances between co-partisan candidates. Following a long tradition in political geography that builds on V.O. Key's classic account of localism and 'friends-andneighbors' voting (Key, 1949), we contend that geographically close co-partisan candidates potentially decrease a candidate's intra-party vote share. The ability of candidates to build an electoral support base of local voters depends on the presence or absence of nearby local candidates on the same list.

The electoral effects of geographic distance and candidate localness are well-documented particularly in majoritarian systems such as the US and UK electoral contexts (e.g. Tatalovich, 1975; Bowler et al., 1993; Rice and Macht, 1987a; Rice and Macht, 1987b; Gimpel et al., 2008; Arzheimer and Evans, 2012; Meredith, 2013; Campbell and Cowley, 2014). Only fairly recently, scholars have started to analyze the role of localism in list proportional representation (PR) electoral systems. Under electoral rules that pit co-partisan candidates against each other, local attributes are instrumental for cultivating personal votes and winning intra-party competition (Shugart et al., 2005).

A growing body of research indeed shows that candidates who are born locally or have locallevel political experience are not only electorally more successful (e.g. Tavits, 2010), but also considered valuable resources by party selectorates in personalized electoral systems (Nemoto and Shugart, 2013). Other work discusses how and which voters look for local candidates (Jankowski, 2016; Blais and Daoust, 2017; Collignon and Sajuria, 2018). Yet despite the scholarly attention to candidate localness, to our knowledge not a single study has examined the role of inter-candidate distance in shaping patterns of competition between candidates.

We expect that inter-candidate distance affects intra-party competition in list PR systems in two different ways. First, the mere geographic distribution of co-partisan candidates over the 
electoral district shapes the level playing field of intra-party competition. If a party nominates multiple candidates that live near each other, party supporters in that area are forced to choose between those local candidates and the nomination strategy can be considered suboptimal, or inefficient (Cheibub and Sin, 2020), from a geographic viewpoint. Spreading out candidates over the electoral district reduces the risk of an overlap between co-partisan candidates' local support bases. Such overlaps can substantially affect candidates' election results and in turn, the course of individual political careers, as recent work documents the effects of intra-party preference vote shares on future list positions and political promotions (Crisp et al., 2013; Folke et al., 2016; André et al. 2017; Meriläinen and Tukiainen, 2018).

Second, the electoral value of earlier mentioned local attributes can work in favor or against a candidate's electoral fortunes in list PR systems. Whereas the positive effect of holding these attributes on personal vote shares is evident, a candidate might also see her vote shares decrease if a nearby located co-partisan exhibits these attributes. The latter can then make a convincing claim of being the best local agent of representation, which will cost votes to co-partisan candidates from the same area.

In this contribution, we provide the first empirical test of the effect that geographic distance between candidates might have on intra-party competition. We use a unique and previously untapped dataset of home address coordinates of 5,077 candidates in four Finnish parliamentary elections (1999-2011). In the Finnish system of open-list proportional representation (OLPR), candidates compete for votes within their party lists and their ranks are determined solely by their personal votes. Moreover, Finnish voters can only cast one single (mandatory) preference vote, which leads to intense intra-party candidate competition for personal votes. A salient intraparty dimension and an institutionalized party system however also structure political competition in Finland, making it relevant to focus on geographical distances among copartisans. Within the context of this study, we consider Finland a most likely case for identifying an inter-candidate distance effect and as such, a good point of departure. The Finnish electoral system is furthermore an interesting reference point, since it can be seen as a representative of what intra-party competition might look like if the ongoing trend towards the personalization of proportional electoral systems in Europe (Renwick and Pilet, 2016) were taken to the extreme.

As the surface area of Finnish electoral districts strongly diverges, pooling the raw distances in kilometers between candidates measured in the various districts in the empirical models might lead to biased or even meaningless results. For instance, a distance of one kilometer between 
two candidates does not have the same meaning in the geographically small and densely populated Helsinki district as in the vast and scarcely populated electoral district of Lapland. Moreover, to get the full picture of how isolated a candidate is vis-à-vis all of her co-partisans on the same list, we need to take into account multiple inter-candidate distances at the same time. For these reasons we develop a novel Candidate Remoteness Index (CRI) which expresses how isolated a candidate is geographically given the surface area and the average distances empirically measured between candidates in that electoral district.

The dependent variable is the intra-party vote share of candidates, which represents a proportion ranging from 0 to 1 . As a result, we run beta regression models to analyze how geographical distance affects these vote shares, which represent the candidate's result in the intra-party competition. Apart from including the CRI, the other independent variables of interest are the local attributes of nearby co-partisan candidates. More specifically, we analyze the effect of nearest located candidates' local birthplace and local-level political experience.

The results show that the positive effect of remoteness on vote shares is mediated by the voter concentration of the candidate's party in her municipality, and also the degree of urbanization of the candidate's municipality. In municipalities with a strong concentration of the party's district voters, large distances towards co-partisans significantly increase intra-party vote shares. Moreover, we find that the advantage of remoteness is significantly stronger for candidates living in rural areas, towns or suburbs than for candidates living in Finnish cities. Furthermore, candidates receive lower vote shares if the nearest located co-partisan has locallevel political experience.

The positive effect of inter-candidate distance is also detected when using the (raw) distance to the nearest candidate instead of CRI, and survives multiple robustness checks. Inter-candidate distances indeed affect electoral outcomes and intra-list electoral rank orders, which potentially has important implications for politicians' careers, party nomination strategies and future empirical research on intra-party competition.

\section{How geographic distance shapes electoral competition}

He [the local candidate] gains support, not primarily for what he stands for or because of his capacities, but because of where he lives.

(Key, 1949, 37) 
With the assertion that gubernatorial candidates in the Southern US states poll overwhelming majorities in their home areas, V.O. Key (1949) sparked the interest of many scholars to study the role of localism in elections. What followed was a range of studies explaining vote shares in various electoral settings, investigating where and for which candidates friends-andneighbors voting is more prevalent, and discussing how the hometown advantage can be measured correctly (Tatalovich, 1973; Johnston, 1974; Rice and Macht, 1987a; Rice and Macht, 1987b; Van Wingen and Parker, 1979). The degree of urbanization, size of the home county, party affiliation and incumbency status were often moved forward as important factors mediating localism effects. Other related work concluded that parties nominate local candidates without real chances of winning seats to cultivate party votes in their areas, a strategy applied by Irish parties especially in rural areas (Parker, 1982).

Another line of research on vote choice and candidate characteristics shows that localism is paramount from the voter perspective. Surveys consistently find that candidate localness is one of the main criteria voters want to see in election candidates or legislators (e.g. Childs and Cowley, 2011; Johnson and Rosenblatt, 2007). Experimental studies have demonstrated that candidate ratings are highly affected by their place of residence (Campbell and Cowley, 2014), local candidate effects are particularly strong amongst voters with weak partisan ties (Roy and Alcantara, 2015), and that voters use local roots as signal to behavioral localism (Campbell et al., 2019).

Pondering on the friends and neighbors voting phenomenon, it is also fitting to evaluate the effects of geographic distance on electoral outcomes. As Gimpel et al. (2008) argue, the more classic studies establishing the mere existence of a hometown advantage should be supplemented by analyses where distance is measured as a continuous predictor of candidate support. Recent empirical work has mainly investigated the effect of candidate-voter distance on vote choice. Arzheimer and Evans $(2012 ; 2014)$ show that vote-likelihood is indeed affected by the distance between a voter and candidates for the three main UK parties, in both general as in county council elections. Linking voter survey data with candidate home addresses, Gorecki and Marsh (2014) demonstrated that friends and neighbors voting can be affected by external events, as was the case in the 2011 Irish elections, when economic crisis influenced voters to prioritize national issues over the local ones. A more recent study on candidate-voter distance shows that voters are also more likely to support candidates in neighboring 
constituencies than further away, and that voters' perceptions of localness matter as well (Evans et al., 2017).

By looking at geographic distance between candidates and voters, the mentioned studies have mainly focused on inter-party electoral competition: how can local candidates attract voters from other parties? Survey research shows that a share of voters is indeed inclined to vote for a local candidate, even if this candidate is not running for the party of preference (Blais and Daoust, 2017; Blais et al., 2003). But distance can play a role in the context of intra-party competition as well, where elections are also battles between candidates within parties (Marsh, 1985). In the comparative literature on intra-party competition, localism has already been identified as an important factor in electoral systems with strong personal vote-seeking incentives. From the voter perspective, a candidate's ties to the local area can serve as information shortcuts to make voting decisions in a highly complex electoral setting (Shugart et al., 2005). From the candidate perspective, these local roots are personal vote-earning attributes and can be strategically applied to cultivate personal votes (Tavits, 2010). Similar to the friends-and-neighbors voting literature, previous work on the personal vote has pointed out that the urban character of the candidate's home turf plays a substantial mediating role in voters' use of preference votes, and in explaining personal electoral successes (e.g. André et al., 2012; Passarelli, 2017). Hicken (2007) argues that candidates in urban areas find it more difficult to develop and maintain a core group of local supporters, as urban voters are less likely to stay in the same place than rural voters (see also: Ramseyer and Rosenbluth, 1993).

There is a clear theoretical link between the concept of friends-and-neighbors voting and local connection as a personal vote-earning attribute. Candidates who make a claim that they have strong ties to the local community and understand local needs foster the type of localism described by Key (1949). Particularly candidates that are town natives, have political experience at the local level or demonstrate their mastery of the local accent can expect to benefit from a considerable hometown advantage. But arguably even those candidates without any of the mentioned attributes are likely to receive a higher vote share in their local area than elsewhere, simply based on their place of residence. Voters' place of residence co-define their social identities, and the place-based component of those identities can also become salient for them when local candidates appear on the ballot (Panagopoulos et al., 2017).

In sum, it is likely that virtually all electoral candidates enjoy a higher degree of electoral support in their own local area than elsewhere. This hometown advantage substantially contributes to candidates' aggregate electoral result at the district level, and therefore also their 
chance of winning a seat and outperforming co-partisans in terms of preference votes. The central argument of this article is that such an advantage - and specifically whether it translates to a significantly better result at the district level - depends on the geographic proximity of other candidates nominated for the same party.

\section{The effect of inter-candidate distance on intra-party competition}

Political parties in list PR systems are incentivized to balance their lists in terms of a number of candidate attributes, such as gender, age, occupation and location (Gallagher and Marsh, 1988; Norris, 2004). Party selectorates that confect balanced tickets cater to the various internal factions and decrease the risk of intra-party turmoil (Valdini, 2012; Arter 2013). Moreover, balancing out the profiles of selected candidates appeals to different sets of voters who are inclined to vote for candidates who are 'like them' (van Erkel, 2019). Carefully crafting a balanced list also reduces the need for co-partisans to engage in overtly fierce intra-party competition, as they seek votes from non-overlapping - geographical and non-geographical constituencies (Cheibub and Sin, 2020). Therefore, ticket-balancing contributes to contained intra-party competition and protects the party brand from the detrimental effects of excessive candidate personalism (Mershon, 2020).

The balancing logic holds for locational characteristics as well, ideally leading to a geographically balanced ballot list with local candidates from different municipalities or areas within the district (Thomsen and Suiter, 2015). The geographic distribution of candidates pleases local party organizations in the different areas within the district and simultaneously appeals to voters in those areas (Put et al., 2018). Ignoring this incentive for geographical balance not only decreases a party's competitiveness, we argue, but also affects intra-party competition dynamics and individual candidate results.

Geographically isolated candidates, who are living in an area within the district where no other intra-party competitor on the list lives nearby, will be more able to build a local electoral support base and hometown advantage. These candidates will therefore receive higher intra-party vote shares at the electoral district level. Party supporters in areas with geographically isolated candidates do not face the dilemma of choosing between different local intra-party competitors. Conversely, areas with strong geographical concentration of candidates do confront local voters with a difficult choice. Candidates in those geographically competitive areas will have to fight 
out who is the best agent of representation for their locality. The result is that nearby living intra-party competitors eat away each other's vote shares.

H1: Geographically remote candidates receive higher intra-party vote shares.

Whereas this hypothesis argues the existence of a general link between candidate distance and intra-party vote shares, previous work suggests that the importance of the distance effect might depend on at least two mediating factors related to the candidate's local area: its urban-rural character, and the geographical concentration of voters of the candidate's party.

Regarding the degree of urbanization, we know that friends and neighbors voting patterns are more prevalent in rural areas, and that rural environments appear more beneficial for attracting a large share of preferential voters. As a consequence, candidates in rural areas of their district will be more sensitive to the geographical proximity of co-partisans than their counterparts located in urban centers. Emphasizing local roots might be a less effective strategy for urban candidates, as urban dwellers move around more frequently (Ramseyer and Rosenbluth, 1993), are more atomized and less integrated in local communities (Nemoto and Shugart, 2013), and therefore less attached to local identities and less aware of candidates' local roots.

As concerns the concentration or dispersion of party voters in the district, candidates in areas with strong voter concentrations might suffer more from nearby located co-partisans. If a candidate lives in an area that does not contribute a large share of the party's support in the district, distance will arguably matter less as this candidate is less likely to attract votes based on the locality argument anyway. After all, the greatest potential for an effective local candidate strategy lies in areas with strong voter concentrations, where the candidate shares her local identity with a great deal of party supporters.

Apart from the candidate perspective, the argument for a mediating role of party voter concentration can be built further from the voter perspective. Following the research on vote choice and candidate characteristics, we know that voters find local representation important and therefore the idea of a locally rooted representative attractive. However, voters also tend to take into account their preferred candidate's chance of getting elected (Lanoue and Bowler, 1998; Barnfield 2019). The result is that voters are more likely to cast a local vote when a local candidate actually stands a chance of getting elected, which tends to be the case in areas with strong voter concentrations for the party. 
In addition to the geographic remoteness of a candidate, we contend that geographic intercandidate distances also affect intra-party vote shares indirectly. Candidates in preferential voting systems compete with all of their intra-party competitors for personal votes at the district level. However, the intra-party battle for local votes - i.e. the voters' support in the candidate's local area - is fought between those candidates that present themselves as suitable agents of representation for the locality.

Candidates convince voters of their awareness for local needs and sensitivities by exhibiting local personal vote-earning attributes. A local voter might be more likely to support candidates who hold a local office or were born in the municipality, compared to candidates lacking these attributes. Whereas earlier work has demonstrated the importance of local roots in explaining individual candidate success (Tavits, 2010; Put and Maddens, 2015), we argue that by the same token these attributes can harm candidates' electoral fortunes.

More specifically, if a candidate faces a nearby living co-partisan who holds local personal vote-earning attributes in the area, this might lead to lower intra-party vote shares. Even if the candidate under consideration exhibits local personal vote-earning attributes herself, a nearby living localized candidate presents a serious local contender in the intra-party arena. We argue that it is particularly the nearest located candidate that affects intra-party vote shares, as other intra-party competitors located further away are more likely to target local voters in other subdistrict areas.

$\mathrm{H} 2$ : If the nearest living intra-party competitor exhibits local personal vote-earning attributes, a candidate receives lower intra-party vote shares.

\section{Intra-party competition in the open-list PR system of Finland}

We situate our study in the Finnish open-list proportional electoral system (OLPR), which can be considered a very suitable initial test bed for the effect of geographical distances on intraparty competition. As other OLPR-systems the Finnish system is highly competitive on the intra-party dimension (Carey and Shugart, 1995), and a very personalized system. A distinctive aspect of the Finnish system, certainly in comparison to most other PR systems, is that the fully open-list makes it impossible for parties to guarantee the election of any individual candidate. In addition, most parties present their candidates in alphabetical order (von Schoultz, 2018), 
which leaves voters without guidance or indicative shortcuts from parties regarding their preferences.

The system does however combine these features with a high degree of inter-party competition, involving an institutionalized party system with eight (relevant) parties and strong party unity in parliamentary voting (Pajala, 2013). Parties are hence significant actors in the Finnish system, and the allocation of seats across parties determines how power is distributed in the Parliament. On this account, Finnish politics very much resembles that of other European proportional electoral systems using closed or flexible lists.

The combination of strong and salient competition both at the intra- and inter-party dimension leads us to expect that the effect of geographical distances under scrutiny in this study, mainly matters for competition within parties. We hence expect voters to prioritize locality when choosing which candidate to vote for, but to do so within the framework of the party that they sympathize with the most. This assumption is further supported by findings from the Finnish National Election Study, where only a minority (of 10 percent) of voters state that they would be willing to vote for their chosen candidate, had that candidate run for a different party (Karvonen, 2012: p. 318). Further, previous research on the electoral success of candidates clearly demonstrate that local roots is a distinct and important aspect in Finnish electoral competition (von Schoultz, 2016). The importance of locality is recognized by parties, who generally strive towards a good regional distribution of nominated candidates (Arter, 2013: p. 104). Based on these observations we consider the Finnish OLPR as a critical case with favorable conditions, i.e. a context in which we consider it very likely that the vote shares of candidates are negatively influenced by geographic proximity of co-partisans.

The 200 seats in the Eduskunta (or Riksdagen in Swedish) are distributed within districts using the D'Hondt highest average method and there is no fixed electoral threshold. During the period 1999-2011 (included in this study), the number of districts on the mainland was 14, and district magnitude (M) ranged from 6 to $35 .^{1}$ The distribution of seats over electoral districts is proportional to the number of Finnish citizens residing in each district. ${ }^{2}$ Districts vary a great deal in terms of geographical size and the number of inhabitants, with the smallest district of Helsinki covering $186,37 \mathrm{~km}^{2}$, and the largest district of Lapland covering $92.856,39 \mathrm{~km}^{2}$.

\footnotetext{
${ }^{1}$ In addition Finland has a single member district, made out of the Swedish-speaking, de-militarized Åland island.

2 The distribution is determined six months before each election based on information from the official population register.
} 
Nomination procedures are regulated by law and decentralized (Karvonen, 2014). Parties are allowed to nominate a maximum of 14 candidates or, if $\mathrm{M}$ exceeds 14 , the number of representatives to be elected. Parties generally field full lists, which makes the system demanding for voters to navigate. In the largest-M constituency of Uusimaa, the total number of candidates in the 2011 election amounted to 406, of which Uusimaa voters were required to single out one candidate for whom to cast their vote. The extensive number of candidates, and the individualized style of campaigning, implies that voters are overloaded with information to process, while receiving little guidance from parties regarding which candidates they consider to be the most qualified.

\section{Data and methods}

This study uses a dataset on candidate characteristics based on public register and bibliographical data covering four parliamentary elections in Finland between 1999 and 2011. The dataset includes the home address geographic coordinates (i.e. eastings and northings) which allow us to calculate the Euclidean straight-line distances between intra-party competitors on the same party list. ${ }^{3}$ Figure 1 plots the place of residence of all candidates in the dataset. Whereas the blue dots represent candidate locations, the Finnish municipalities are colored in gray gradient where darker implies a stronger presence of candidates in the municipality. The map shows substantial differences between districts in terms of candidate distributions and densities. As district magnitude is determined by the demographic weight of each electoral district, we see stronger candidate densities in the southern, more populated districts of Finland. Furthermore, in each electoral district the candidates are clustered in and around the largest cities and metropolitan areas to account for the larger share of voters in those areas.

\footnotetext{
${ }^{3}$ Information on the nominated candidates for parliamentary elections in Finland was requested and received from the Ministry of Justice, which functions as the election authority in Finland, and from the Population Register Centre. The public register of home addresses kept by the Population Register Centre is continuously updated and is considered to be very accurate. The home addresses are derived from the register 31 days before the Election Day, when the nomination of all candidates is made official. Coordinates for home addresses were provided by the Population Register Centre in KKJ-format which is the Finnish uniform coordinate system, and were later transformed into ETRS89 coordinates.
} 


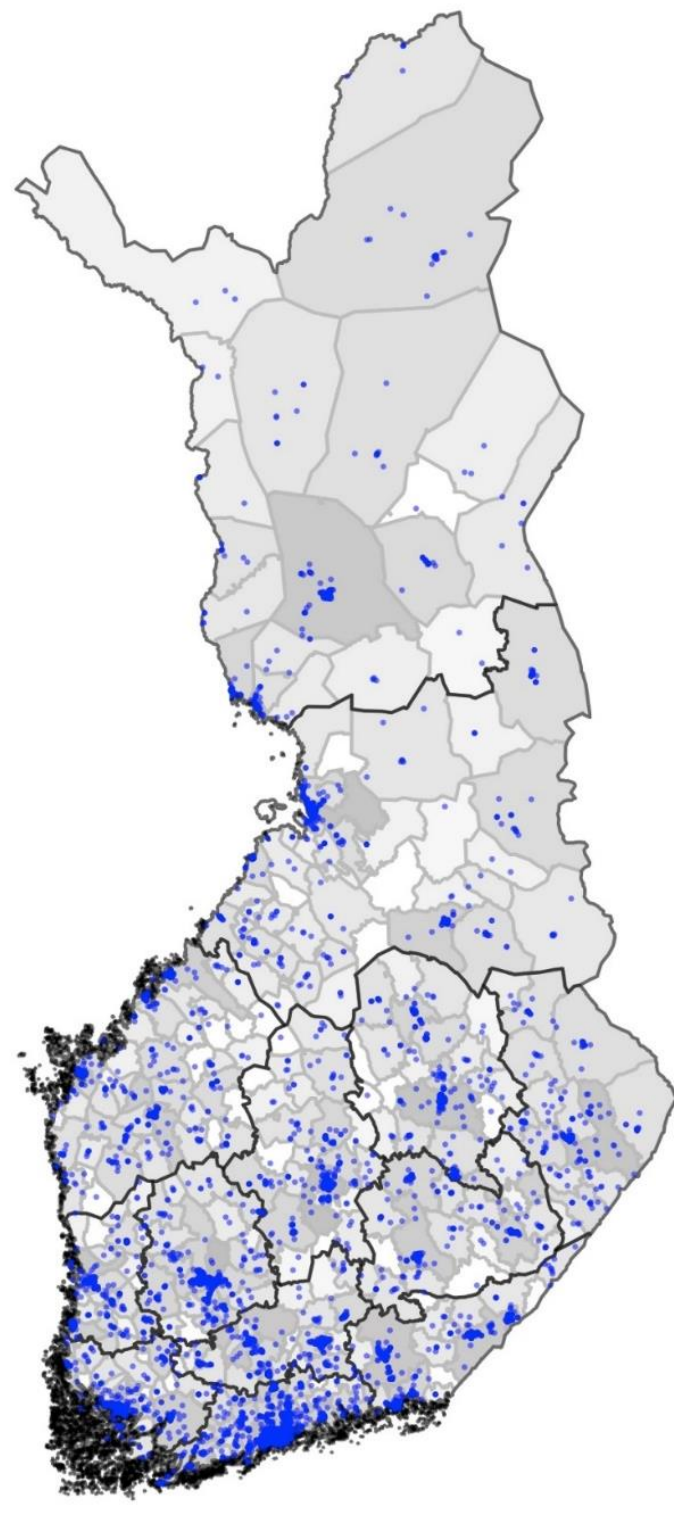

$\log$ (Number of candidates)

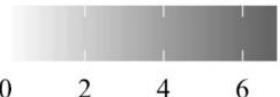

Figure 1: Location of election candidates for the 1999-2011 parliamentary elections in Finland.

Furthermore, the dataset also includes candidate-level information on sociographic characteristics, political experience, electoral fortunes and party-political context. The independent variables of interest are inter-candidate distances and the local attributes of nearest co-partisan candidates. For each candidate we registered the local roots, operationalized as holding a local office or being born in the home municipality, the distance to all the co-partisan 
candidates on the list ${ }^{4}$ and the local attributes of the nearest candidate. Specifically, we examine the effect of the nearest candidate's local-level political experience (i.e. holding office at the local level) and being born locally (i.e. in the home municipality).

A key challenge is how to operationalize inter-candidate geographic distances and subsequently model its effect on intra-party vote shares. As regards the operationalization, earlier work on candidate-voter distances uses (a logarithmic transformation of) raw distance, measured in kilometers (e.g. Gorecki and Marsh, 2012; Gorecki and Marsh, 2014; Evans et al., 2017). We contend that following the established practice in our study potentially leads to biased results for at least two reasons. First, contrary to the mentioned studies on candidate-voter distances we are the first - to our knowledge - to analyze candidate-to-candidate distances in large multimember districts with often extensive numbers of candidates on party lists. As parties distribute co-partisan candidates geographically over the surface of the entire electoral district, our operationalization needs to take into account multiple inter-candidate distances. Arguably, the geographic distance to the nearest located competitors has a larger impact on the intra-party vote share than distances to candidates relatively further away in the district. This implies that the chosen operationalization needs to express a weighted outcome of inter-candidate distances. Second and most importantly, Finnish electoral districts vary substantially in terms of geographic surface. As a result, inter-candidate distances are naturally larger in the vast districts of Oulu and Lapland than in the smaller districts of Satakunta, Uusimaa and especially Helsinki. This is also clear from Figure 1, which showed a stark contrast between the northern districts and the more urbanized southern districts of the country.

Figure 2 shows a boxplot of the distance to the nearest co-partisan candidate, grouped by electoral district. For each candidate in the dataset, we registered the raw distance (in kilometers) to the nearest candidate on the same list. The grouped boxplot shows substantial differences between the districts in terms of both the mean (diamond) and median observation, and also regarding the variation in distances to the nearest co-partisan. Not surprisingly, the contrast between the hyper urbanized district of Helsinki and the geographically vast and less densely populated Oulu and Lapland is striking, which fuels our concerns for using raw distances in the statistical models. For every district, the long upper whisker shows that the

\footnotetext{
${ }^{4}$ If a candidate was part of an electoral alliance comprising candidates from two or more different parties, the distance is calculated to the nearest candidate on the list from the same party, not the nearest candidate within the alliance in general.
} 
distances to nearest candidates are more varied among the upper quartile group. In Lapland, the highest values exceed 340 kilometers and exclusively represent candidates living in Utsjoki, the northernmost municipality in Finland bordering Norway.

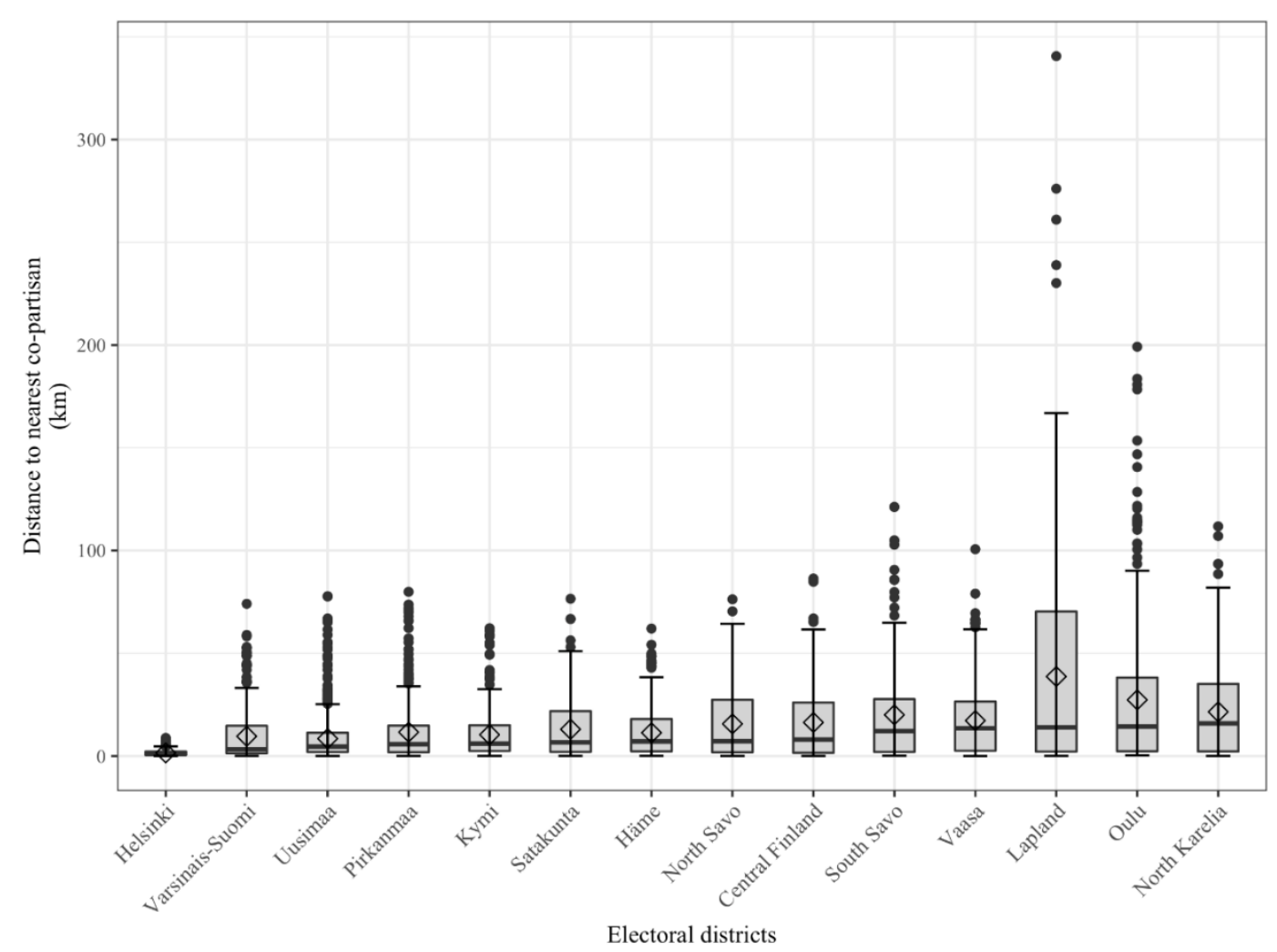

Figure 2: Grouped boxplot of distance to nearest co-partisan candidate, per electoral district.

We propose using a Candidate Remoteness Index (CRI), which takes into account the differences between electoral districts in terms of geographic surface, and mean inter-candidate distances. Instead of using and weighting the raw distances (in kilometers) to intra-party competitors, we group these competitors into geographic zones or concentric circles around each of the candidates. The radius of these concentric circles varies over the districts to make these zones comparable. More specifically, the radius of the first concentric circle around each candidate equals the standard deviation of the grand mean inter-candidate distance in the district. ${ }^{5}$ The radius of the second circle equals two times the standard deviation, and for the

\footnotetext{
${ }^{5}$ This grand mean was calculated per district over all candidates in all election years included in the dataset. Put another way, for each electoral district we have a grand mean inter-candidate distance and its corresponding standard deviation.
} 
third and fourth it is three and four times the standard deviation respectively. This results into four zones around each candidate, demarcated by concentric circles, and an additional fifth zone outside of the fourth circle that constitutes the remainder of the district.

Subsequently, for each candidate we count the number of co-partisan candidates in each of these five geographic zones, and attach weights to the candidate numbers in each zone. In line with the argument that nearest co-partisans are more important than distant co-partisans, the weights decrease as we move further away from the candidate. As a final step, we subtract this score from 1 in order that high scores imply stronger remoteness and low scores imply shorter distances to co-partisans. More generally, the Candidate Remoteness Index (CRI) is calculated according to this formal notation:

$$
C R I=1-\frac{\sum_{i=1}^{n} \frac{n-i+1}{n} \cdot C_{i}}{\sum_{i=1}^{n} C_{i}}
$$

Where $\mathrm{n}$ represents the total number of concentric circles or geographic zones around the candidate, and $C_{i}$ stands for the number of co-partisans in the i-th circle or zone. In the specific case of using five zones, the weights incrementally decrease from 1 (i.e. $\frac{5}{5}$ ) to 0.2 (i.e. $\frac{1}{5}$ ). The weighted sum of co-partisan candidates is then divided by the total number of co-partisan candidates.

To illustrate this approach, Figure 3 provides an example of a candidate running for the Social Democratic Party (SDP) in the electoral district of Pirkanmaa during the 2003 parliamentary elections. Only one co-partisan candidate is located within the first concentric circle and two within the second circle. The majority of co-partisans are located within the third concentric circle which covers Tampere, the capital city of this electoral district. The example also shows that while the four concentric circles cover most of the geographic surface of the Pirkanmaa district, outside of the fourth circle constitutes a fifth additional zone including the remainder of co-partisan candidates on the list. This specific distribution of candidates adds up to a CRI score of 0.42 . 


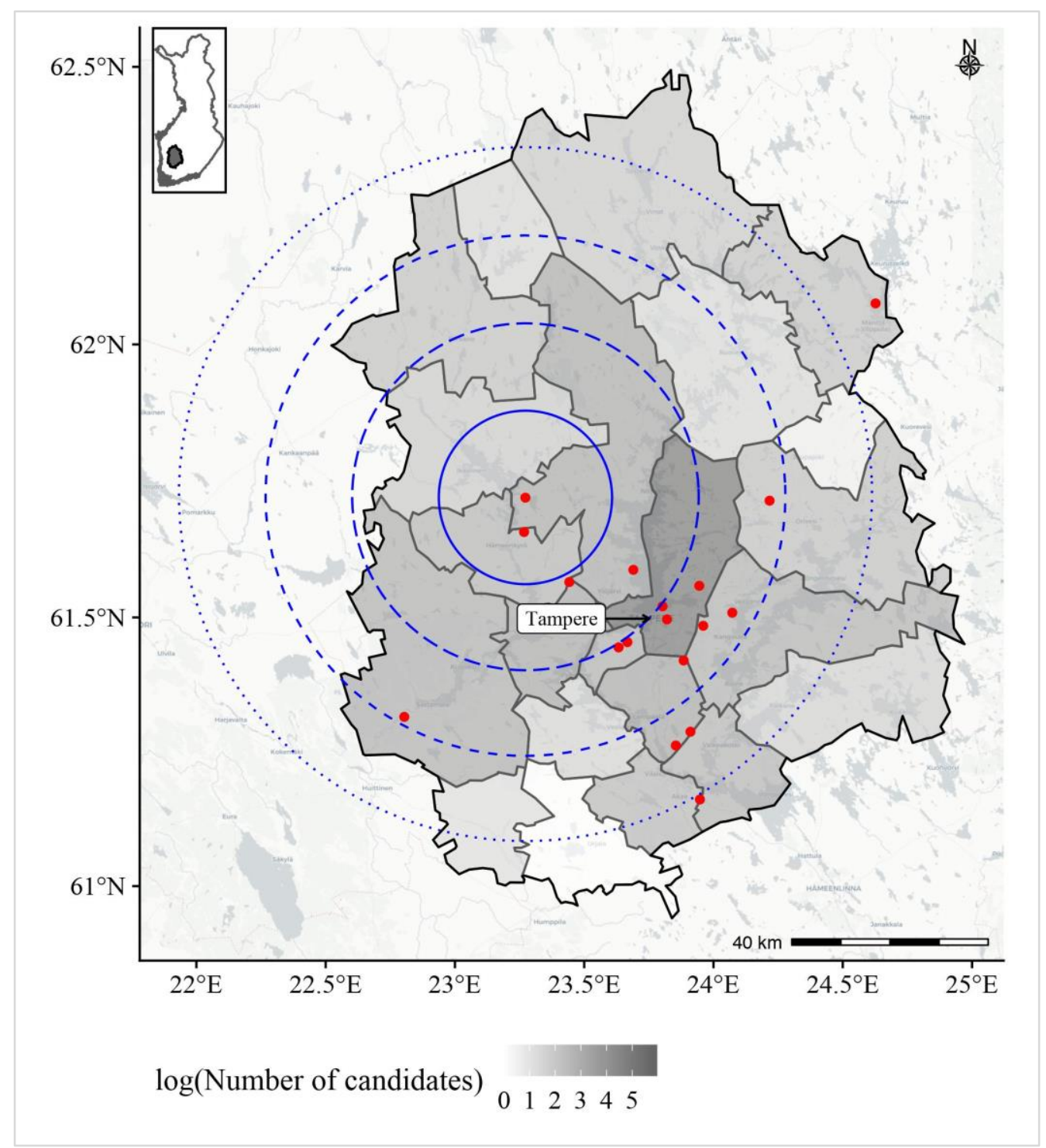

Figure 3: Example of the concentric circles approach used for the calculation of the Candidate Remoteness Index (CRI).

This index constitutes the main independent variable of interest, next to the binary variables focusing on the nearest co-partisan candidate's local personal vote-earning attributes: 'locallevel political experience' (1: elected councilor in the previous municipal election; 0: not elected in the previous municipal election) and 'municipality native' (1: born in home municipality; 0: not born in home municipality). We also take into account the candidates' own local personal vote-earning attributes.

We include the two potentially mediating variables for the effect of distance, degree of urbanization and party voter concentration, as follows. In order to measure the urban/rural 
character of each candidate's municipality, we apply Eurostat's ${ }^{6}$ territorial typology on the degree of urbanization, which classifies all Finnish ${ }^{7}$ (and other countries') local administrative units as either 1) cities, 2) towns and suburbs, or 3) rural areas, based on a combination of geographical contiguity and population density using $1 \mathrm{~km}^{2}$ population grid cells. ${ }^{8}$

Party voter concentration is a variable that expresses which share of the party's district voters is located in the municipality of the candidate. Self-evidently, these municipal party voter shares will be positively correlated with intra-party vote shares, but also offer a measure of the potential success of a local candidate strategy. To test for their mediating role in explaining the effect of distance, the empirical models will include interaction terms between CRI and both variables.

Including these two variables, which measure within-district variation between municipalities in terms of urban character and voter concentration, has two notable consequences for our sample size. First, as we only have data on the geographical concentration of voters for the eight political parties in Finland with consistent parliamentary representation, ${ }^{9}$ we have to exclude smaller parties and lists from regionally based parties from the analysis. Second, candidate observations from the electoral district of Helsinki present a problem as well, as the district borders perfectly coincide with the capital city's borders. This makes it impossible to account for within-district differences regarding urbanity and party voter concentrations: the Helsinki district consists of local administrative unit, which leads to one Eurostat score 'City' for the entire district and the unavailability of sub-district municipal party voter concentrations.

In addition to this research design related argument, we believe the Helsinki district is a deviant case for additional reasons. As Helsinki is the capital and the political, administrative and economic center, the value of locality in voting behavior is degraded and local representation is a less important concern for Helsinki voters. Previous research indeed shows that voters' emphasis on the role of locality increases with distance from the capital (Bengtsson and Wass,

\footnotetext{
${ }^{6}$ Eurostat stands for European Statistical Office and is a Directorate-General of the European Commission.

${ }^{7}$ As we make use of the 2011 edition of the urbanization typology, some of the Finnish municipalities that merged between 1999 and 2011 were missing from the dataset. We assigned them to the category of rural areas, as merging municipalities are more likely to be small and sparsely populated. Nevertheless, to account for potential bias caused by this decision, we also compared the results using this approach with an alternative one where we assign the merged municipalities to the category of the larger municipality to which they belonged in 2011, which did not lead to different results.

${ }^{8}$ More detailed information on the methodology, and full access to the data can be found at:

https://ec.europa.eu/eurostat/web/nuts/local-administrative-units .

${ }^{9}$ Social Democratic Party (SDP), National Coalition Party (KOK), Centre Party (KESK), Green League (VIHR), Left Alliance (VAS), Swedish People's Party (RKP), Finns Party (PS) and Christian Democrats (KD).
} 
2011). Moreover, all voters' place of residence in this district perfectly coincide with practically all candidates running in the Helsinki district. This leads us to exclude the 560 candidates running in the Helsinki district from the empirical models presented in the article. The dataset that will be used in these models therefore includes 5,077 candidates. ${ }^{10}$

Table 1 and 2 provide a number of descriptive statistics on the continuous and discrete variables used in the analysis. Regarding the CRI, Table 1 shows that the index score ranges from 0 to 0.80 as a result of the weighted proportions of co-partisan candidates distributed over the different concentric circles. The maximal score of 0.80 implies that all co-partisans are located in the fifth and most remote zone around the candidate. The minimal score of 0 instead means that all intra-party competitors live near - i.e. within the first concentric circle - the candidate under consideration.

Table 1: Descriptive statistics for continuous variables used in the analysis $(n=5,077)$.

\begin{tabular}{lcccc}
\hline & $\overline{\mathrm{x}}$ & sd. & Min. & Max. \\
\hline CRI & 0.38 & 0.19 & 0.00 & 0.80 \\
N candidates on list & 18.56 & 7.23 & 2 & 35 \\
District voter concentration & 0.15 & 0.16 & 0.00 & 0.75 \\
Intra-party vote share & 0.06 & 0.08 & 0.00 & 0.78 \\
\hline
\end{tabular}

In Table 2, more details are provided on the candidates' own local personal vote-earning attributes and those of the nearest co-partisan. Looking at the candidates' own characteristics, we see that a majority of observations in the dataset are not born in their home municipality (63.90\%), but there is a majority of candidates having local-level political experience $(56.94 \%)$. These percentages are very similar for the nearest candidate, but not identical as a particular candidate can be the nearest co-partisan for several intra-party competitors.

\footnotetext{
${ }^{10}$ The raw dataset on the four included elections contains 8,341 candidates. The number of included observations was reduced to 5,077 for the following reasons: missing data on home address coordinates, candidates who were running as a single candidate on the party list (impossible to calculate the distance to co-partisan candidates), candidates who have their home municipality in another district than where they were nominated, candidates from the Åland islands as it constitutes the only single-member district in Finland, candidates running for parties not having consistent parliamentary representation over the observed years, and finally candidates running in the Helsinki district.
} 
Table 2: Descriptive statistics for discrete independent variables of interest $(n=5,077)$.

\begin{tabular}{llcc}
\hline Variable & Levels & $\mathrm{n}$ & $\%$ \\
\hline Nearest candidate & & & \\
Municipality native & Yes & 1,765 & 34.76 \\
& No & 3,312 & 65.24 \\
Local-level experience & Yes & 2,860 & 56.33 \\
& No & 2,217 & 43.67 \\
Incumbent MP & Yes & 626 & 12.33 \\
& No & 4,451 & 87.67 \\
Candidates' own characteristics & & & \\
Municipality native & Yes & 1,833 & 36.10 \\
& No & 3,244 & 63.90 \\
Local-level experience & Yes & 2,891 & 56.94 \\
Incumbent MP & No & 2,186 & 43.06 \\
& Yes & 563 & 11.09 \\
& No & 4,514 & 88.91 \\
\hline
\end{tabular}

Our dependent variable is the candidate's share of the total number of votes received by the candidates on the party list, which we refer to as the intra-party vote share. Since these values are proportions ranging from 0 to 1 (see Table 1), applying linear regression will yield out-ofbound estimates for some of the predicted values. A flexible approach for modeling continuous proportional data is beta regression (Ferrari et al., 2004). This type of model requires values on the dependent variable to lie between 0 and 1 and allows for asymmetry in vote proportions. ${ }^{11}$ Candidate vote shares are affected by a complex web of determinants. The analysis therefore takes into account a set of additional covariates that co-explain intra-party vote shares. First, we control for the incumbency status of both the candidate and nearest intra-party competitor. Candidates that already served in parliament during the previous term are more likely to dominate intra-party competition than 'challengers' who have no prior parliamentary experience. Table 2 reports that only a low share $(11.09 \%)$ of the candidates included in the analysis are running in the election as incumbent MP.

Second, the number of candidates on the list is controlled for, as this negatively affects vote shares. Indeed, longer party lists systematically lead to lower vote shares for individual

\footnotetext{
${ }^{11}$ Another commonly applied approach to analyze vote shares (see e.g. Shugart and Taagepera, 2017) is to take the logarithmic transformation and run a linear model instead. We report the results of this approach as an additional robustness test in the online appendix.
} 
candidates. Third, we include additional candidate characteristics that might explain individual electoral results, such as candidate gender and age. ${ }^{12}$ Finally, party and election year dummies are included in all the models to capture the unobserved heterogeneity that might come with this type of cross-sectional data.

\section{Results}

This section discusses the results of beta regression models explaining candidates' intra-party vote shares (see Table 3). ${ }^{13}$ To begin with, we run a model including the independent variables of interest, mediating variables (without modelling interactions with distance), control variables and fixed effects. Subsequently, we include interaction terms of inter-candidate distance, measured by the CRI, with district voter concentration and urban-rural character. After presenting the results, we discuss the interpretation of the interaction effects and model coefficients more generally to understand its importance in intra-party competition.

Model I does not bring support for $\mathrm{H} 1$ on the effect of inter-candidate geographic distance on intra-party vote shares. According to this beta regression model, it does not make a difference whether a candidate is geographically isolated from her co-partisans in the district, or instead lives near multiple co-partisans. Looking at the characteristics of the nearest intra-party competitor (H2), we find that only one of the local personal vote-earning attributes affects vote shares. Facing a nearest candidate who holds a local office decreases one's own electoral score significantly. The size of the effect is smaller compared to when facing a nearby incumbent, which harms a candidate the most.

On the contrary, facing a nearest candidate who was born in the municipality where she currently lives is not related to intra-party success. The same holds for candidates who themselves are born in the municipality where they live. These null findings corroborate earlier reservations on using birthplace as indicator of local roots. As argued by Tavits (2010), the birthplace of a candidate may not be a publicly known piece of information, or even convey meaningful information as the candidate might as well have lived somewhere else after birth.

\footnotetext{
${ }^{12}$ Due to space limitations, we show the results of a model excluding candidates' professional categories as control variables, which did not have a significant effect on intra-party vote shares. We present the results of a model including coefficients for different professional categories in the Online Appendix.

${ }^{13}$ All models are estimated in SAS STAT, using PROC GLIMMIX. In all models, standard errors are clustered at the party list level.
} 
In sum, $\mathrm{H} 2$ is confirmed only for one operationalization of local personal vote-earning attributes, i.e. facing a nearest candidate with local-level experience.

Table 3: Beta regression models explaining intra-party vote shares of Finnish candidates, 1999-2011.

\begin{tabular}{lcccc}
\hline & \multicolumn{2}{c}{ Model I } & \multicolumn{2}{c}{ Model II } \\
\hline & coef. & (se) & coef. & (se) \\
\hline Candidate Remoteness Index (CRI) & 0.15 & $(0.10)$ & -0.19 & $(0.17)$ \\
Nearest candidate characteristics & & & & \\
Municipality native & & & & \\
Local-level experience & -0.04 & $(0.03)$ & -0.04 & $(0.03)$ \\
Incumbent MP & $-0.13^{* * *}$ & $(0.03)$ & $-0.12^{* * *}$ & $(0.03)$ \\
& $-0.17^{* * *}$ & $(0.04)$ & $-0.18^{* * *}$ & $(0.04)$
\end{tabular}

Candidate's own characteristics

Municipality native

$\begin{array}{cccc}-0.06 & (0.03) & -0.05 & (0.03) \\ 0.47 * * * & (0.04) & 0.47 * * * & (0.04) \\ 1.49 * * * & (0.05) & 1.47 * * * & (0.05)\end{array}$

Local-level experience

$1.49 * * 2$.

Mediating variables

District voter concentration

$1.60 * * * \quad(0.16) \quad 0.41$

Cities

$-0.37 * * * \quad(0.05) \quad 0.04$

Rural areas

$-0.13 * * *$

(0.04) $\quad-0.02$

(ref.= Towns and suburbs)

Interaction effects

$\mathrm{CRI} *$ District voter concentration

$4.93 * * *$

CRI * Cities

$-1.32 * * *$

$-0.14$

CRI * Rural Areas

Controls

Number of candidates on list

$$
\begin{array}{ccc}
-0.05 * * * & (0.00) & -0.05 * * * \\
-0.02 & (0.03) & -0.01 \\
-0.00 & (0.00) & -0.00
\end{array}
$$

Candidate gender (ref=Male)

Candidate age

Election year FE

Included

Included

Party FE

Included

Included

Constant

$-2.60 * * * \quad(0.13) \quad-2.53 * * * \quad(0.13)$

\section{$\mathrm{N}$}

5,077

5,077

Significance levels: $* * *: p<0,001 ; * *: p<0,01 ; *: p<0,05$. Clustered standard errors between brackets. FE = fixed effects.

We find the expected result for local-level experience of the observed candidate. In line with earlier empirical work on local PVEA (Shugart et al., 2005; Tavits, 2010; Put and Maddens, 
2015; von Schoultz, 2016), a Finnish election candidate holding local office on average receives considerably higher vote shares. Furthermore, incumbency status yields the strongest effect of all candidate-level characteristics, corroborating the expectation that incumbents generally dominate intra-list competition and attract the highest share of preference votes. As concerns the mediating variables, we see that both city candidates and rural area candidates receive on average lower vote shares than candidates from the reference category 'Towns and suburbs'. Unsurprisingly, candidates in municipalities with strong concentration of their party's district voters receive much higher vote shares. Finally, other candidate-level controls (i.e. age, gender) do not yield statistically significant effects on intra-party vote shares.

In order to analyze whether the role of geographic distance depends on characteristics of the candidate's local area, Model II includes interaction terms between CRI and the potentially mediating variables 'degree of urbanization' and 'district voter concentration'. Regarding the candidate and nearest candidate characteristics $(\mathrm{H} 2)$, the results are identical to Model I. However, we arrive at highly different findings as concerns inter-candidate distance. First, the positive and significant interaction between CRI and district voter concentration shows that candidates who live in areas with a large share of their party's electorate in the district benefit from increased geographic remoteness vis-à-vis their co-partisans. If, on the contrary, the candidate is living in a municipality that does not contribute a large share of votes for her party in the district, the distance to intra-party competitors does not play an important role. Therefore, if multiple candidates from the same area are running for election on the same party list, and their party draws a lot of electoral support in that area, these candidates will receive higher vote shares if they live more dispersed over the area.

Figure 4 visualizes this interaction effect between voter district concentration and CRI while holding all other covariates at their respective means (continuous) or modal values (categorical). We see that the predicted vote share of candidates increases in areas where their party has a relatively large number of voters (i.e. we visualize the effect for a voter district concentration of $22.67 \%$, which is the value of the third quartile). In areas with a lower number of party voters (i.e. voter district concentration of $3 \%$, which is the value of the first quartile of this conditioning variable), the distance to co-partisans does not make a difference in terms of intra-party successes. 


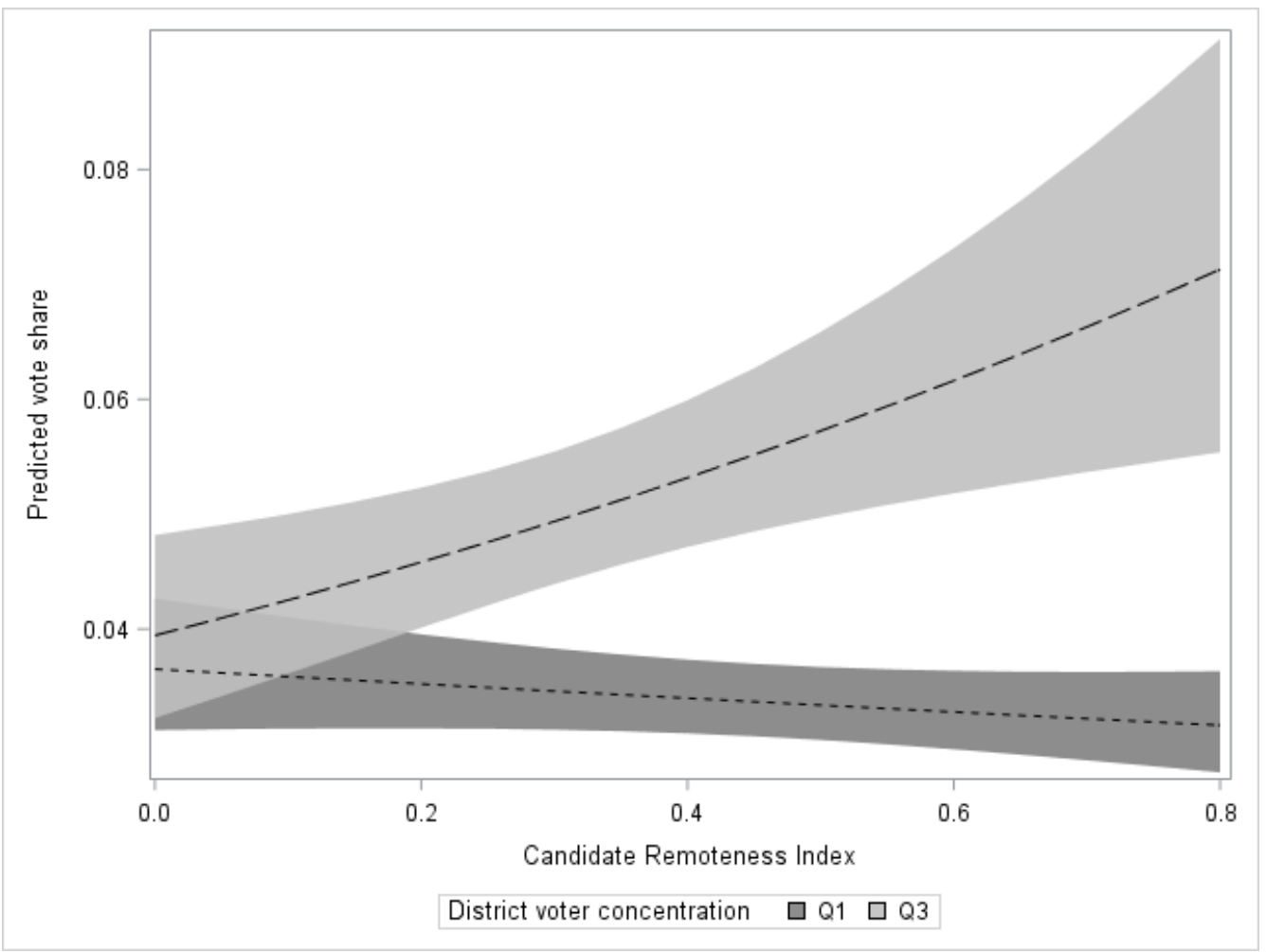

Figure 4: Visualization of the interaction effect between district voter concentration and CRI-score, based on Model II.

Model II also shows that the role of distance depends on the urban character of the candidate's municipality. The potentially positive effect of being remotely located appears significantly lower when the candidate lives in an urban area compared to candidates in suburban or rural areas. This finding appears to be in line with earlier work showing that local voting dynamics work different in rural and urban areas. As urban voters are less driven by local credentials in their voting behavior than rural and suburban voters, the electoral bonus associated with distance towards intra-party competitors is significantly lower among urban candidates. In fact, the model even shows that urban candidates who are geographically isolated seem to receive significantly lower vote shares than their counterparts in less urbanized areas. It seems that in urban areas, candidates who are located further away from their co-partisans and the urban center are less able to dominate intra-party competition than candidates closer to their urban colleagues. This might also be caused by the fact that urban candidates who are located in the outskirts of the city are less able to dominate the campaign or are primarily nominated by the parties to 'cover' the peripheral areas of the city.

Figure 5 shows this interaction effect between distance and the degree of urbanization, while holding other covariates at their respective means or modal values. Whereas candidates living 
in rural or suburban municipalities clearly benefit from higher remoteness vis-à-vis intra-party competitors, candidates in urban settings in fact see their vote shares significantly decrease when CRI scores are high.

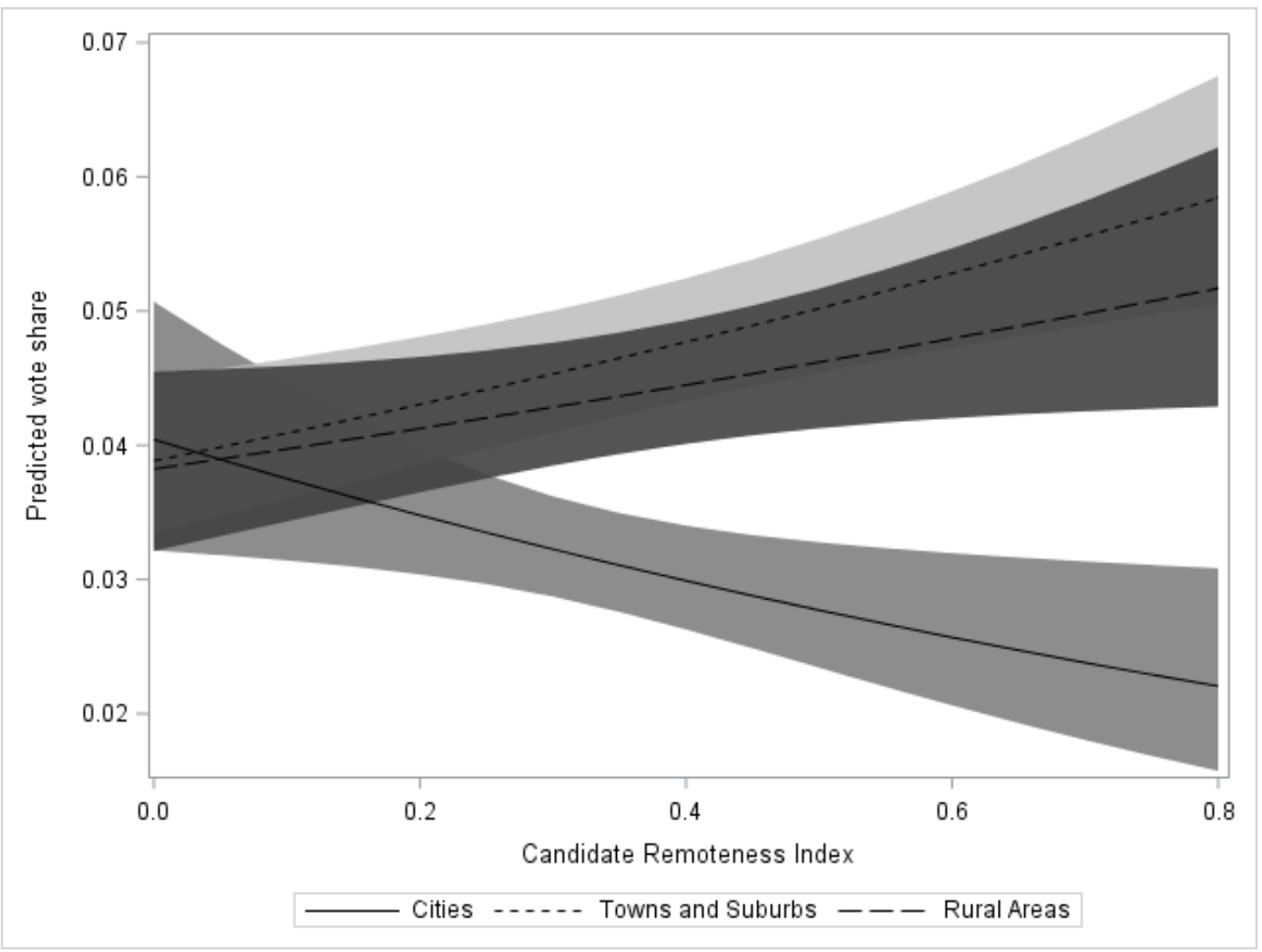

Figure 5: Visualization of the interaction effect between degree of urbanization and CRI-score, based on Model II.

The Online Supplemental Material presents the results of a number of additional models to test for the robustness of our findings. Table A shows a model with an additional set of interaction effects to test for the relative strength of local PVEA. Moreover, this model includes interaction terms between inter-candidate distance and the nearest candidate characteristics to check whether the effect of distance is also conditional on the strength of nearby located candidates. This beta regression with interaction effects produces two new meaningful results. First, the positive effect of holding local office decreases when the candidate simultaneously is an incumbent. Incumbent candidates cannot fully capitalize on the value of their local experience, as their credibility from the voters' perspective is already shaped by their previous political experience in parliament, not at the local level. Second, we find that the bonus of incumbency status is significantly reduced if the nearest candidate is also an incumbent. This results suggests 
that clustering multiple incumbents in the same geographical area results in fierce competition for local votes and weakens the intra-party success of these incumbents.

Table B uses the distance to the nearest candidate (in kilometers) instead of the Candidate Remoteness Index to analyze the effect of inter-candidate distance on intra-party vote shares. The results point in the same direction, i.e. distance increases vote shares in suburban and rural areas with strong district voter concentrations. In urban areas, on the contrary, distance seems to decrease the candidates' result. A notable difference with the results using CRI reported in Table 3 is that the coefficient for distance to nearest candidate is significant and negative, indicating that the level of district voter concentration needs to pass a certain threshold for the candidate to not face an electoral setback.

Next, Table C shows the coefficients of an OLS regression model using CRI as independent variable of interest. The results confirm that higher scores on the index increase intra-party vote shares only when district voter concentrations are high, and that isolated candidates in cities receive significantly lower vote shares. An OLS regression using logged intra-party vote share (Table D) corroborates these findings as well. Table E shows the results for a beta regression model that does not only include age and gender as control variables, but also the occupational categories of candidates (following the ILO classification). Although occupational categories clearly affect vote shares, again the main results of this contribution are not affected. Table F provides another strict robustness test by including electoral district fixed effects that remove all unobserved heterogeneity in the outcome related to differences in districts. In line with the other analyses, we find evidence for the complex relationship between distance, district voter concentration, urban-rural character of the area and intra-party vote shares.

\section{Conclusion}

Despite the longstanding tradition in political geography that builds on V.O. Key's classic account of localism and 'friends-and-neighbors' voting (Key, 1949), previous studies on intraparty competition have largely neglected how this effect is played out in interaction with other candidates running for the same list.

In this study we have contributed to the growing literature on intra-party competition by running a unique test of the extent to which candidates' ability to build an electoral support base depends on the presence or absence of nearby local candidates on the same list. Our study is situated 
within the Finnish open-list PR system; a democracy combining an institutionalized party system with a highly salient intra-party dimension, shaped by mandatory preferential voting and (mostly) alphabetical ordering of candidates.

We have used hitherto unexplored data on more than 5,000 candidates' home address coordinates in combination with data on their political experiences and electoral results over four consecutive parliamentary elections (1999-2011). To measure the remoteness of a particular candidate while taking into account the great geographical variation across Finnish electoral districts, we developed a novel index, a Candidate Remoteness Index (CRI), based on the distribution of co-partisans over concentric circles around that candidate.

The results, based on beta-regression models and a number of robustness-checks, show that candidate-to-candidate distances matter for how votes are distributed within parties. Remotely located candidates receive significantly higher vote shares than candidates living in sub-district areas that are more densely populated in terms of intra-party competitors. The effect of geographical remoteness is however contingent on local party strength and on the degree of urbanization: candidates particularly benefit from more distant co-partisans in party strongholds and rural and suburban municipalities. Moreover, we establish that a candidates' electoral result depends on the political experiences of nearby living candidates. Candidates facing an incumbent MP or a local-level incumbent as their nearest intra-party competitor, win on average lower vote-shares.

Our findings have potentially important implications. For scholars interested in understanding the mechanisms of intra-party competition under proportional representation, it is clearly important to look beyond the characteristics of the individual candidates, their electoral experience and their roots in the local community. Competition is shaped by the pool of candidates nominated for the same party, and - as we have demonstrated - how these candidates are distributed geographically within a district, taking into account parties' local support and the degree of urbanization. For experienced politicians and for party practitioners responsible for selection processes, these findings hardly come as a surprise. A good geographical distribution is generally considered as a successful strategy to maximize votes, and there is plenty of anecdotal evidence of MPs maneuvering or lobbying inside their parties to side step potential local challengers.

Our contribution further highlights the importance of taking into account the geographical location of intra-party competitors in selection processes, since it is likely to have substantial 
effects on how electoral support is distributed across candidates competing for votes within the same party, and, in turn, on the future political careers of candidates. Not only are vote margins between the last winner and first loser on Finnish party lists very small, the post-electoral rank of an elected candidate (i.e. the order of candidates according to their preference votes) is often used by party elites as a criterion to allocate national or local level executive positions. As a result, geographical isolation allows politicians to hop over a few competitors in the intra-party hierarchy and boost their political status both in- and outside of the party.

Based on the empirical analyses presented in this article, we are unable to assess whether intercandidate distances also matter for inter-party competition. In line with the literature on ticketbalancing, the locational characteristics of candidates can in a similar way as other crucial characteristics (e.g. ethnicity, occupation, age) be balanced on the list so as to avoid intraorganizational turmoil (Valdini, 2012). Moreover, excluding specific geographical areas from the list might similarly decrease the party's overall competitiveness. From both the inter- and intra-party competition perspective, it is however important to acknowledge that the average party hardly face an unlimited supply of candidates, and that strategic intentions may fail to materialize when facing the harsh reality of candidate recruitment.

Admittedly, Finland is a most likely case for identifying an inter-candidate distance effect as described in this article, and a confirmatory finding in such a setting indeed makes it difficult to assess the extent to which the result is generalizable to other contexts. The combination of a purely open-list PR system with a single mandatory preference vote breeds strong competition between candidates from the same list, and most definitely between co-partisan candidates fishing in the same pond of local voters. Where voters are allowed to cast multiple preference votes, the dynamics of intra-party competition might be substantially different and candidates from the same local area may be incentivized to combine forces instead of targeting each other's local support bases. Our empirical explorations should therefore be considered as a point of departure, and regarding future research efforts, it would therefore be particularly interesting to investigate an open or flexible list case with multiple preference voting, such as Belgium, Greece, Iceland, Latvia, Norway or Slovakia.

We have developed a theoretical argument for the existence of a distance effect, and demonstrated empirically that the location of candidates vis-à-vis co-partisans matters. As political campaigning becomes more candidate centered cross-nationally (Langer, 2007), voters in list PR systems are becoming more preoccupied with individual candidates and their personal characteristics (Karvonen, 2010), and electoral systems are becoming more personalized 
(Renwick and Pilet, 2016), we believe that Finland will not turn out to be the unique case showing strong inter-candidate distance effects.

\section{References}

André, A., Depauw, S., Shugart, M. S., \& Chytilek, R. (2017). Party nomination strategies in flexible-list systems: Do preference votes matter?. Party Politics, 23(5), 589-600.

André, A., Wauters, B., \& Pilet, J. B. (2012). It's not only about lists: Explaining preference voting in Belgium. Journal of Elections, Public Opinion \& Parties, 22(3), 293-313.

Arter, D. (2013). The 'Hows', not the 'Whys' or the 'Wherefores': The Role of Intra-party Competition in the 2011 Breakthrough of the True Finns. Scandinavian Political Studies, 36(2), 99-120.

Arzheimer, K., \& Evans, J. (2012). Geolocation and voting: Candidate-voter distance effects on party choice in the 2010 UK general election in England. Political Geography, 31(5), 301-310.

Arzheimer, K., \& Evans, J. (2014). Candidate geolocation and voter choice in the 2013 English County Council elections. Research \& Politics, 1(2), 2053168014538769.

Barnfield, M. (2019). Think Twice before Jumping on the Bandwagon: Clarifying Concepts in Research on the Bandwagon Effect. Political Studies Review, https://doi.org/10.1177/1478929919870691

Bengtsson, Å., \& Wass, H. (2011). The Representative Roles of MPs: A Citizen Perspective. Scandinavian Political Studies, 34(2):143-167.

Blais, A., \& Daoust, J. F. (2017). What do voters do when they like a local candidate from another party?. Canadian Journal of Political Science/Revue canadienne de science politique, 50(4), 1103-1109.

Blais, A., Gidengil, E., Dobrzynska, A., Nevitte, N., \& Adeau, R. (2003). Does the local candidate matter? Candidate effects in the Canadian election of 2000. Canadian Journal of Political Science/Revue canadienne de science politique, 36(3), 657-664.

Bowler, S., Donovan, T., \& Snipp, J. (1993). Local sources of information and voter choice in State elections: microlevel foundations of the" friends and neighbors" effect. American Politics Quarterly, 21(4), 473-489.

Campbell, R., \& Cowley, P. (2014). What voters want: Reactions to candidate characteristics in a survey experiment. Political Studies, 62(4), 745-765. 
Campbell, R., Cowley, P., Vivyan, N., \& Wagner, M. (2019). Why friends and neighbors? Explaining the electoral appeal of local roots. The Journal of Politics, 81(3), 937-951.

Carey, J. M., \& Shugart, M. S. (1995). Incentives to cultivate a personal vote: A rank ordering of electoral formulas. Electoral studies, 14(4), 417-439.

Cheibub, J. A., \& Sin, G. (2020). Preference vote and intra-party competition in open list PR systems. Journal of Theoretical Politics, 32(1), 70-95.

Childs, S., \& Cowley, P. (2011). The politics of local presence: Is there a case for descriptive representation?. Political Studies, 59(1), 1-19.

Collignon, S., \& Sajuria, J. (2018). Local means local, does it? Regional identification and preferences for local candidates. Electoral Studies, 56, 170-178.

Crisp, B. F., Olivella, S., Malecki, M., \& Sher, M. (2013). Vote-earning strategies in flexible list systems: Seats at the price of unity. Electoral Studies, 32(4), 658-669.

Evans, J., Arzheimer, K., Campbell, R., \& Cowley, P. (2017). Candidate localness and voter choice in the 2015 General Election in England. Political Geography, 59, 61-71.

Ferrari, S., \& Cribari-Neto, F. (2004). Beta regression for modelling rates and proportions. Journal of applied statistics, 31(7), 799-815.

Folke, O., Persson, T., \& Rickne, J. (2016). The primary effect: Preference votes and political promotions. American Political Science Review, 110(3), 559-578.

Gallagher, M., \& Marsh, M. (1988). Candidate selection in comparative perspective: The secret garden of politics (Vol. 18). Sage Publications Ltd.

Gimpel, J. G., Karnes, K. A., McTague, J., \& Pearson-Merkowitz, S. (2008). Distance-decay in the political geography of friends-and-neighbors voting. Political Geography, 27(2), 231252.

Górecki, M. A., \& Marsh, M. (2012). Not just 'friends and neighbours': Canvassing, geographic proximity and voter choice. European Journal of Political Research, 51(5), 563-582.

Górecki, M. A., \& Marsh, M. (2014). A decline of 'friends and neighbours voting'in Ireland? Local candidate effects in the 2011 Irish 'earthquake election'. Political Geography, 41, 1120.

Hicken, A. D. (2007). How do rules and institutions encourage vote buying? In F.C. Schaffer, ed., Elections for Sale: The Causes and Consequences of Vote Buying, Boulder and London: Lynne Riener.

Jankowski, M. (2016). Voting for locals: Voters' information processing strategies in open-list PR systems. Electoral Studies, 43, 72-84. 
Johnson, C., \& Rosenblatt, G. (2007). Do MPs have the 'right stuff'?. Parliamentary Affairs, 60(1), 164-169.

Johnston, R. J. (1974). Local effects in voting at a local election. Annals of the Association of American Geographers, 64(3), 418-429.

Karvonen, Lauri (2010). The personalization of politics. A study of parliamentary democracies. Colchester: ECPR Press.

Karvonen, Lauri (2012) “Ehdokasäänesäminen”. Muutosvaalit 2011. Helsinki: Oikeusministeriö. Selvityksiä ja ohjeitä. 16/2012.

Karvonen, Lauri (2014). Parties, governments and voters in Finland. Politics under fundamental societal transformation. Colchester: ECPR Press.

Key, V. O., Jr. (1949). Southern politics in state and nation. New York: A.A. Knopf.

Lanoue, D. L., \& Bowler, S. (1998). Picking the Winners: Perceptions of Party Viability and Their Impact on Voting Behavior. Social Science Quarterly, 79(2), 361-377.

Marsh, M. (1985). The voters decide?: Preferential voting in European list systems. European Journal of Political Research, 13(4), 365-378.

Meredith, M. (2013). Exploiting friends-and-neighbors to estimate coattail effects. American Political Science Review, 107(4), 742-765.

Meriläinen, J., \& Tukiainen, J. (2018). Rank effects in political promotions. Public Choice, 177(1-2), 87-109.

Mershon, C. (2020). Challenging the wisdom on preferential proportional representation. Journal of Theoretical Politics, 32(1), 168-182.

Nemoto, K., \& Shugart, M. S. (2013). Localism and coordination under three different electoral systems: The national district of the Japanese House of Councillors. Electoral Studies, 32(1), $1-12$.

Norris, P. (2004). Electoral engineering: Voting rules and political behavior. Cambridge university press.

Pajala, Antti (2013). Government vs Opposition Voting in the Finnish Parliament Eduskunta since World War II. European Journal of Government and Economics, 2(1), 41-58.

Panagopoulos, C., Leighley, J. E., \& Hamel, B. T. (2017). Are Voters Mobilized by a 'Friendand-Neighbor'on the Ballot? Evidence from a Field Experiment. Political Behavior, 39(4), $865-882$.

Parker, A. (1982). The 'friends and neighbours' voting effect in the Galway West constituency. Political Geography Quarterly, 1(3), pp. 243-262. doi:10.1016/0260-9827(82)90013-1. 
Passarelli, G. (2017). Determinants of preferential voting in Italy: General lessons from a crucial case. Representation, 53(2), 167-183.

Put, G. J., \& Maddens, B. (2015). The effect of municipality size and local office on the electoral success of Belgian/Flemish election candidates: a multilevel analysis. Government and Opposition, 50(4), 607-628.

Put, G. J., Smulders, J., \& Maddens, B. (2018). How local personal vote-earning attributes affect the aggregate party vote share: Evidence from the Belgian flexible-list PR system (2003-2014). Politics, 0263395718811969.

Ramseyer, M., \& Rosenbluth, F. M. (1993). Japan's political marketplace. Harvard University Press.

Renwick, A., \& Pilet, J. B. (2016). Faces on the ballot: The personalization of electoral systems in Europe. Oxford: Oxford University Press.

Rice, T. W., \& Macht, A. A. (1987a). Friends and neighbors voting in statewide general elections. American Journal of Political Science, 448-452.

Rice, T. W., \& Macht, A. A. (1987b). The hometown advantage: mobilization or conversion?. Political Behavior, 9(3), 257-262.

Roy, J., \& Alcantara, C. (2015). The candidate effect: Does the local candidate matter?. Journal of Elections, Public Opinion \& Parties, 25(2), 195-214.

Shugart, M. S. \& Taagepera, R. (2017). Votes from seats: Logical models of electoral systems. Cambridge: Cambridge University Press.

Shugart, M. S., Valdini, M. E., \& Suominen, K. (2005). Looking for locals: voter information demands and personal vote-earning attributes of legislators under proportional representation. American Journal of Political Science, 49(2), 437-449.

von Schoultz, Å. (2016). Passing through the Eye of the Needle - Individual Electoral Success in Finnish Parliamentary Elections. In Raunio, T., \& L. Karvonen, eds., The Changing Balance of Political Power in Finland, Stockholm: Santerus Academic Press.

von Schoultz, Å. (2018) 'Electoral systems in context: Finland'. In Herron, E., R. Pekkanen \& M. S. Shugart, eds., Oxford Handbook of Electoral Systems, Oxford: Oxford University press.

Tatalovich, R. (1975). " Friends and Neighbors" Voting: Mississippi, 1943-73. The Journal of Politics, 37(3), 807-814.

Tavits, M. (2010). Effect of local ties on electoral success and parliamentary behaviour: The case of Estonia. Party Politics, 16(2), 215-235. 
Thomsen, S., \& Suiter, J. (2015). Candidates, parties and constituency relations. The Act of Voting: Identities, Institutions and Locale. London: Routledge, 161-177.

Valdini, M. E. (2012). A deterrent to diversity: The conditional effect of electoral rules on the nomination of women candidates. Electoral Studies, 31(4), 740-749.

van Erkel, P. F. (2019). Sharing is caring: the role of voter-candidate similarities in intra-party electoral competition. European Political Science Review, 11(1), 75-89.

Van Wingen, J. R., \& Parker, J. B. (1979). Measuring friends-and-neighbors voting. American Politics Quarterly, 7(3), 367-383. 